\title{
Effect Formazan of Benzaldehyde as Corrosion Inhibitor on Preventing the Mild Steel Corrosion in Acidic Medium
}

\author{
B. ANAND \\ Department of Chemistry, Mahendra Engineering College, Namakkal-637503, India \\ chemanad27@gmail.com
}

Received 12 December 2012 / Revised 23 January 2013 / Accepted 10 February 2013

\begin{abstract}
The effect of formazan of benzaldehyde (FB) on the corrosion of mild steel in acidic media $(1 \mathrm{M} \mathrm{HCl}$ and $2 \mathrm{M} \mathrm{HCl})$ has been investigated using weight loss measurements, electrochemical studies and surface analysis. These studies have also shown that formazan of benzaldehyde is a good inhibitor for mild steel in $1 \mathrm{M} \mathrm{HCl}$ and $2 \mathrm{M} \mathrm{HCl}$ acid solutions at room temperature in $2 \mathrm{~h}$. In $1 \mathrm{M}$ $\mathrm{HCl}$ the inhibition efficiency was high when compared to $2 \mathrm{M} \mathrm{HCl}$ acid solutions. The surface analysis also confirms the corrosion inhibition of the mild steel by the inhibitor (FB).
\end{abstract}

Keywords: Mild steel, Weight loss, SEM, Acid inhibition, Polarization

\section{Introduction}

The value of mild steel used in a vast area of applications has strengthened the research area in terms of corrosion resistance in various aggressive environments ${ }^{1-3}$. Several researchers have devoted their attention to develop more effective and non-toxic inhibitors of iron. The use of inhibitors like organic inhibitor is one of the most practical methods for the protection of mild steel against corrosion especially in acidic medium ${ }^{4-9}$. Numbers of organic compounds have been studied in detail as the corrosion inhibitors to reduce both acid attack and protection aspects in mild steel. However, the use of organic inhibitors in acid solutions leads to prevent corrosion resistance ${ }^{10-14}$. Organic compounds containing Oxygen, Nitrogen, Sulphur and tiple bonds have been reported as good corrosion inhibitors ${ }^{15-16}$. Many nitro and nitroso have been tried as corrosion inhibitors ${ }^{17}$. Organic corrosion inhibitors can be conjugation and nature of bonding atoms. Certain azo-compounds like methyl orange and methyl red show effective inhibition due to their anodic, cathodic or mixed type depending on its size, carbon chain length, atomicity. Many quinines such as anthroquinone and its derivatives act as oxidative passivators ${ }^{18}$. The use of organic compounds based corrosion inhibitors against metal dissolution is often associated with chemical and/or physical adsorption, involving a variation in the charge of adsorbed substance and a transfer of charge from one phase to other. Special interest was paid to the effect of electron donating on the atom or electron withdrawing or a group which is responsible for adsorption mainly 
due to on steric factors, aromaticity, the structural properties of the organic compounds studied. The presence of $\pi$ - electrons and heteroatoms, which induce greater adsorption of the inhibitor molecules over the surface of mild steel. Therefore, in this study, the corrosion inhibition of mild steel in $1 \mathrm{M} \mathrm{HCl}$ and $2 \mathrm{M} \mathrm{HCl}$ solution was studied in the presence and absence of the inhibitor for two hours at room temperature.

\section{Experimental}

According to ASTM method as reported already ${ }^{19}$, mild steel strips were cut into pieces of $5 \mathrm{~cm} \times 1 \mathrm{~cm}$ having the following composition (in percentage) $\% \mathrm{C}=0.017 ; \mathrm{Si}=0.007$; $\mathrm{Mn}=0.196 ; \mathrm{S}=0.014 ; \mathrm{P}=0.009 ; \mathrm{Ni}=0.013 ; \mathrm{Mo}=0.015 ; \mathrm{Cr}=0.043$ and $\mathrm{Fe}=99.686$ was used. The samples were polished, drilled a hole at one end and numbered by punching. During the study the samples were polished with various grades of $\mathrm{SiC}$ abrasive papers (from grits 120 to 1200) and degreased using Acetone.

\section{Preparation of solutions}

All the solutions were prepared using NICE brand analar grade chemicals in double distilled water and bubbling purified by nitrogen gas for 30 minutes to carry out de-aeration of the electrolytes. $1 \mathrm{M} \mathrm{HCl}$ and $2 \mathrm{M} \mathrm{HCl}$ solutions were prepared by double distilled water. Inhibitor solution of formazan of benzaldehyde (FB) was prepared by dissolving $0.1 \mathrm{~g}$ of formazan of benzaldehyde (FB) in $100 \mathrm{~mL}$ of test solution. The structure is shown in Figure 1.<smiles>CN(C)c1ccc(/C(=N/NC(N)=O)NNc2ccccc2)cc1</smiles>

Figure 1. Formazan of benzaldehyde (FB)

\section{Weight loss measurement}

Mild steel specimens were immersed $1 \mathrm{M} \mathrm{HCl}$ and $2 \mathrm{M} \mathrm{HCl}$ for $2 \mathrm{~h}$ at room temperature $\left(28 \pm 2{ }^{\circ} \mathrm{C}\right)$ for each inhibitor concentration. Then the specimens were removed, rinsed in double distilled water, acetone and the loss in weight of the specimen was determined. From this, the inhibiton efficiency (IE \%) was calculated using the formula

$$
\mathrm{IE} \%=\frac{\mathrm{W}_{\mathrm{o}}-\mathrm{W}_{\mathrm{i}} \times 100}{\mathrm{~W}_{\mathrm{o}}}
$$

Where, $\mathrm{W}_{\mathrm{O}}$ and $\mathrm{Wi}$ (in $\mathrm{g}$ ) are the values of the weight loss observed of mild steel in the presence and absence of inhibitor respectively.

\section{Electrochemical studies}

All the electrochemical measurements were performed using the Electrochemical Workstation Model No: CHI 600D, CH Instruments, USA) at a constant temperature of $28 \pm 2{ }^{\circ} \mathrm{C}$ maintained with $1 \mathrm{M} \mathrm{HCl}$ and $2 \mathrm{M} \mathrm{HCl}$ as an electrolyte. A platinum electrode and a saturated calomel electrode (SCE) were used as auxiliary and reference electrodes. The working electrode comprised of mild steel specimen with $1 \mathrm{~cm}^{2}$ of exposed area. The tip of 
the reference electrode was carefully positioned very close to the surface of the working electrode by the use of a fine Luggin capillary in order to minimize the ohmic potential drop. The remaining uncompensated resistance was also reduced by the electrochemical workstation. Potentiodynamic polarization studies were carried out at a scan rate of $0.01 \mathrm{mV} \mathrm{s}^{-1}$ and at a potential range of -800 to $-200 \mathrm{mV}$ for optimum concentration of the inhibitors. The electrochemical impedance studies were carried out in the same setup as that of potentiodynamic polarization studies and the applied ac perturbation signal was about $10 \mathrm{mV}$ within the frequency range $1 \mathrm{~Hz}$ to $1 \mathrm{KHz}$. All the electrochemical impedance measurements were carried out at open circuit potential. The percentage of the inhibition efficiency is calculated from the values of the current density $\left(\mathrm{I}_{\text {corr }}\right)$ with aid of the following formula

$$
\mathrm{IE} \%=\frac{\mathrm{I}_{\text {corr }}-\mathrm{I}_{\text {corr(i) }} \times 100}{\mathrm{I}_{\text {corr }}}
$$

$I_{\text {corr }}=$ Corrosion current density in the absence of inhibitor, $I_{\text {corr }}(i)=$ Corrosion current density in the presence of inhibitor.

\section{Scanning electron microscope (SEM analysis)}

The mild steel specimens were immersed in the blank $(1 \mathrm{M} \mathrm{HCl}$ and $2 \mathrm{M} \mathrm{HCl})$ containing the inhibitor Formazan of benzaldehyde (FB) for $2 \mathrm{~h}$ after which they were taken out, washed with distilled water and then the specimens was observed under Scanning Electron Microscope (SEM- HITACHI S3000H, Japan).

\section{FT-IR studies}

The corrosion products formed on the steel surface during weight loss measurement was removed by crumbing and was used for recording FT-IR spectra. This study reveals the possibility of the adsorption of the inhibitor on the metal surface. The Fourier transform infrared (FT-IR) spectra of the frayed films were recorded using a (Perkin Elmer-1400) FTIR spectrophotometer.

\section{Results and Discussion}

\section{Weight loss method}

The comparison graph of corrosion behaviour and inhibitor efficiency of mild steel in $1 \mathrm{M} \mathrm{HCl}$ and $2 \mathrm{M} \mathrm{HCl}$ with Formazan of benzaldehyde (FB) which was studied by weight loss method at $2 \mathrm{~h}$ at room temperatures was given in Figure 2 (a) \& (b). From the graph, it was observed that the weight loss of mild steel in the acid decreases with increasing concentration of additives and the values were tabulated in Table 1 from which it was clear that the corrosion rate has decreased with increasing concentration of inhibitor and inhibition efficiency increased with increasing the concentration of the inhibitor. In addition, the maximum corrosion inhibition efficiency of Formazan of benzaldehyde (FB) was $43.00 \%$ at $1 \mathrm{M} \mathrm{HCl}$ and $37.87 \%$ at $2 \mathrm{M} \mathrm{HCl}$ respectively at $36.85 \mathrm{mM}$ concentration of the inhibitor solution for two hours at room temperature.

It was also fulfilled that the inhibitor was very efficient for the prevention of mild steel corrosion in $1 \mathrm{M} \mathrm{HCl}$ and $2 \mathrm{M} \mathrm{HCl}$ and when comparing with acids, the inhibitor efficiency was maximum in $1 \mathrm{M} \mathrm{HCl}$ than $2 \mathrm{M} \mathrm{HCl}$. Figure 2(a) revealed the comparison of corrosion rate (CR) with concentration of formazan of benzaldehyde (FB) (in \%) in $1 \mathrm{M} \mathrm{HCl}$ and $2 \mathrm{M}$ $\mathrm{HCl}$ solution at two hour at room temperature. Comparison of inhibition efficiency (IE) with concentration of (FB) (in \%) in $1 \mathrm{M} \mathrm{HCl}$ and $2 \mathrm{M} \mathrm{HCl}$ solution for two hours at room temperature is shown in Figure 2(b). 


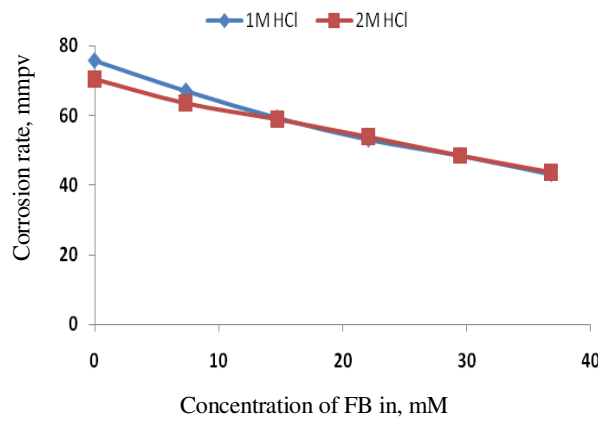

Figure 2(a). Comparison of corrosion rate (CR) with concentration of formazan of benzaldehyde (FB) (in \%) in $1 \mathrm{M} \mathrm{HCl}$ and $2 \mathrm{M} \mathrm{HCl}$ solution at two hour

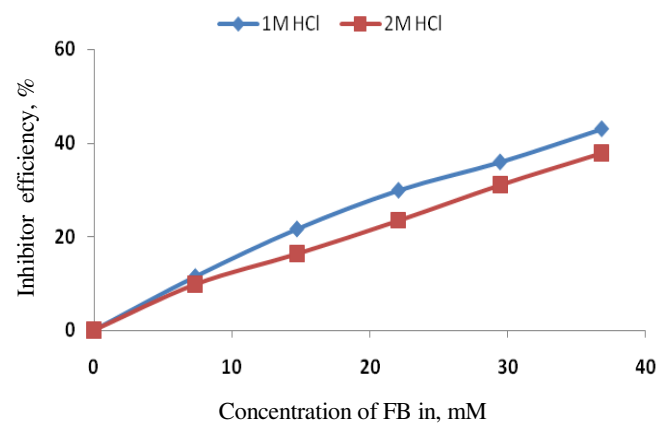

Figure 2(b). Comparison of inhibition efficiency (IE) with concentration of (FB) (in $\%$ ) in $1 \mathrm{M} \mathrm{HCl}$ and $2 \mathrm{M} \mathrm{HCl}$ solution for two hour

Table 1. Corrosion parameters in absence and presence of formazan of benzaldehyde (FB) with $1 \mathrm{M} \mathrm{HCl}$ and $2 \mathrm{M} \mathrm{HCl}$

\begin{tabular}{cccccc}
\hline \multirow{2}{*}{ Inhibitor } & \multirow{2}{*}{$\begin{array}{c}\text { Conc. of } \\
\text { inhibitor, mM }\end{array}$} & \multicolumn{2}{c}{ Corrosion rate } & \multicolumn{2}{c}{ Inhibitor } \\
\cline { 3 - 6 } & & \multicolumn{2}{c}{$\mathrm{mm} / \mathrm{y}$} & \multicolumn{2}{c}{ Efficiency, \% } \\
\cline { 3 - 6 } & Blank & 75.6748 & 70.3251 & --- & --- \\
Formazan of & 7.37 & 66.9816 & 63.4152 & 11.48 & 9.82 \\
benzaldehyde & 14.74 & 59.2916 & 58.8458 & 21.64 & 16.32 \\
$($ FB) & 22.11 & 53.0503 & 53.8305 & 29.89 & 23.45 \\
& 29.48 & 48.4809 & 48.4809 & 35.93 & 31.06 \\
& 36.85 & 43.1312 & 43.6885 & 43.00 & 37.87 \\
\hline
\end{tabular}

\section{Adsorption isotherm}

Basic information on the interaction between the inhibitor and the mild steel surface can be proved by the adsorption isotherm and in general, inhibitors can function either by physical (electrostatic) adsorption or chemisorption with the metal. To acquire more information about the interaction between the inhibitor molecules and the metal surface, different adsorption isotherms were tested. The fractional surface coverage $\theta$ at different concentrations of inhibitors in $1 \mathrm{M} \mathrm{HCl}$ and $2 \mathrm{M} \mathrm{HCl}$ solutions were determined from the weight loss measurements data ${ }^{20}$ using the formula,

$$
\theta=\frac{\mathrm{Wo}_{\mathrm{O}}-\mathrm{Wi}}{\mathrm{Wo}}
$$

Where, Wo and Wi are the values of weight loss of uninhibited and inhibited specimens, respectively.

$$
K c=\frac{\theta}{1-\theta}
$$

Where, $\mathrm{c}$ is the concentration of the inhibitor, $\theta$ is the fractional surface coverage. The Langmuir isotherm, Eq. (4), which is based on the assumption that all adsorption sites are equivalent and also states that whether the nearby sites are occupied or not. It was verified for the studied inhibitors. The adsorption equilibrium constant $K$ is related to the free energy of adsorption $\Delta \mathrm{G}_{\mathrm{ads}}$ as: 


$$
K=\frac{1}{C_{\text {solvent }}} \exp \left(\frac{-\Delta G_{a d s}}{R T}\right)
$$

Where, $\mathrm{C}_{\text {solvent }}$ represents the molar concentration of the solvent, which in the case of water is $55.5 \mathrm{~mol} \mathrm{dm}^{-3}, \mathrm{R}$ is the gas constant and $\mathrm{T}$ is the thermodynamic temperature in $\mathrm{K}$. The Langmuir isotherm, Eq. (5), can be rearranged to obtain the following expression,

$$
\frac{c}{\theta}=\frac{1}{K}+c
$$

So that a linear-relationship can be obtained on plotting $\mathrm{c} / \theta$ as a function of $\mathrm{c}$, with a slope of unity. The thermodynamic parameters $\mathrm{K}$ and $\Delta \mathrm{G}_{\mathrm{ads}}$ for the adsorption of the studied inhibitors on mild steel is obtained by Langmuir's adsorption isotherm are plotted in Figure 3 and the obtained values are shown in Table 2. It was found that the linear correlation coefficients clearly prove that the adsorption of the formazan of benzaldehyde (FB) from $1 \mathrm{M} \mathrm{HCl}$ than $2 \mathrm{M} \mathrm{HCl}$ solutions on the mild steel corrosion obeys the Langmuir adsorption isotherm. The negative values of $\Delta \mathrm{G}_{\text {ads }}^{0}$ for the addition of inhibitors indicate that the process of adsorption of studied inhibitors is spontaneous in nature ${ }^{21}$. The free energy of adsorption of $\left(\Delta \mathrm{G}_{\mathrm{ads}}\right)$, in $1 \mathrm{M} \mathrm{HCl}$ was found to be $-6.548 \mathrm{kJmol}^{-1}$ while for $2 \mathrm{M} \mathrm{HCl}$ it was found to be $-5.290 \mathrm{kJmol}^{-1}$ respectively.

$$
\text { - } 1 \mathrm{M} \mathrm{HCl} \quad \text { \ } 2 \mathrm{M} \mathrm{HCl}
$$

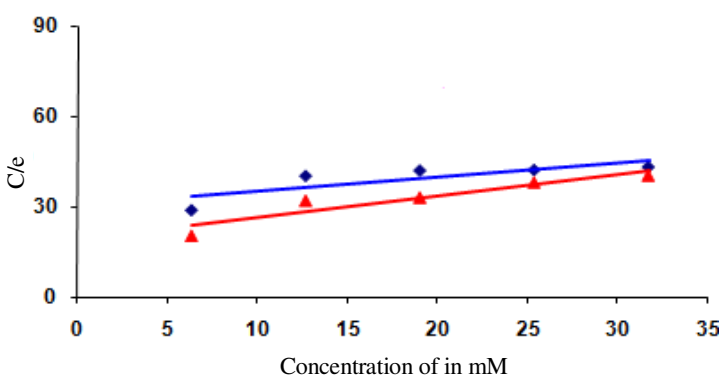

Figure 3. Langmuir isotherm for adsorption of FB on mild steel surface studied at $(1 \mathrm{M} \mathrm{HCl}$ and $2 \mathrm{M} \mathrm{HCl}$ )

Table 2. Thermodynamic parameters for the adsorption of $\mathrm{FB}$ in $(1 \mathrm{M} \mathrm{HCl}$ and $2 \mathrm{M} \mathrm{HCl})$ on the mild steel

\begin{tabular}{ccccc}
\hline Name of the acid & $\begin{array}{c}\text { Concentration in } \\
\mathrm{mM}\end{array}$ & $\begin{array}{c}\text { Surface } \\
\text { coverage }(\theta)\end{array}$ & $\begin{array}{c}\Delta \mathrm{G}_{\text {ads }} \\
\mathrm{kJ} / \mathrm{mol}^{-1}\end{array}$ & $\begin{array}{c}\mathrm{K} \times 10^{-2} \\
\mathrm{M}^{-1}\end{array}$ \\
\hline $1 \mathrm{M} \mathrm{HCl}$ & 36.85 & 0.4300 & -6.548 & 1.80 \\
$2 \mathrm{M} \mathrm{HCl}$ & 36.85 & 0.3787 & -5.290 & 1.80 \\
\hline
\end{tabular}

It is well known that the values of $\Delta \mathrm{G}_{\mathrm{ads}}$ in the order of $-20 \mathrm{~kJ} \mathrm{~mol}^{-1}$ or lower indicate a physisorption while those about $-40 \mathrm{~kJ} \mathrm{~mol}^{-1}$ or higher involve charge sharing or transfer from the inhibitor molecules to the metal surface to form a co-ordinate type of bond ${ }^{22}$.

The calculated adsorption values for the studied inhibitor at different acidic medium show that the adsorption is of physical in nature and there is no chemisorption between the inhibitor molecule and the metal surface. This indicates that the adsorption of FB at $2 \mathrm{~h}$ takes place through electrostatic interaction between the inhibitor molecule and the metal surface. Hence it indicates that the physical adsorption takes place between the inhibitor molecule and metal surface is physisorption. 


\section{Potentiodynamic polarization studies}

Potentiodynamic polarization results obtained for the inhibitory effect of formazan of benzaldehyde (FB) on mild steel corrosion in $1 \mathrm{M} \mathrm{HCl}$ and $2 \mathrm{M} \mathrm{HCl}$ are depicted clearly in Figure 4(a) \& (b). The various polarization parameters such as corrosion current ( $\left.\mathrm{I}_{\text {corr }}\right)$, corrosion potential $\left(\mathrm{E}_{\mathrm{corr}}\right)$, anodic and cathodic Tafel slopes $(-\beta \mathrm{a}$ and $-\beta \mathrm{c})$ were derived from potentiodynamic polarization studies on mild steel in both acidic medium.

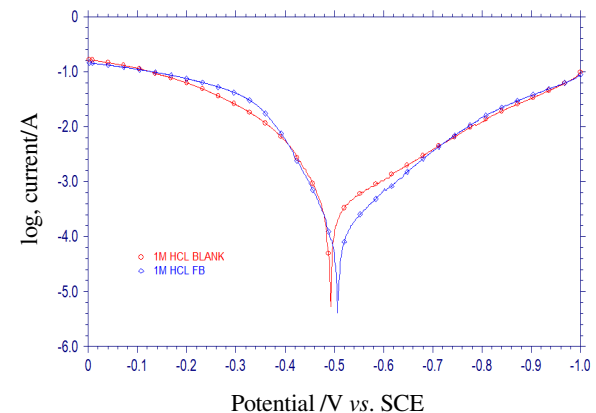

Figure 4(a). Potentiodynamic polarization curves of mild steel in $1 \mathrm{M} \mathrm{HCl}$ in the absence and presence of the inhibitor

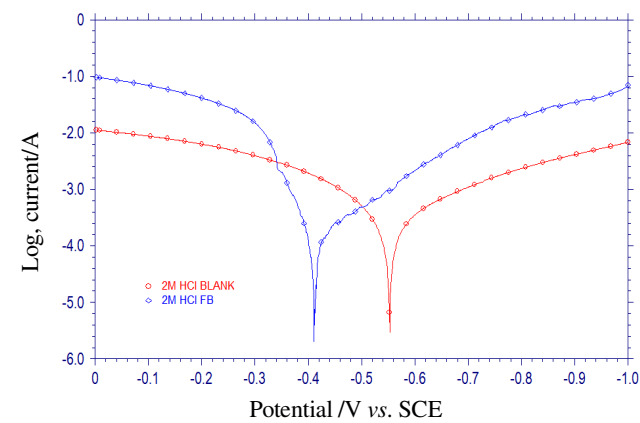

Figure 4(b). Potentiodynamic polarization curves of mild steel in $2 \mathrm{M} \mathrm{HCl}$ in the absence and presence of the inhibitor

It has been experimentally verified from the Table 4 that the $E_{\text {corr }}$ values have been shifted slightly towards negative side in the presence of inhibitors suggesting that the inhibitors inhibit the corrosion of mild steel in acidic solutions by controlling cathodic reactions due to the blocking of active sites on the metal surface. It is evident that inhibitors bring about considerable polarization of the cathode. It shows that the inhibitive action of FB is of mixed type inhibitor. The corresponding results of potentiodynamic polarization parameters are represented in Table 3.

Table 3. Polarization parameters of mild steel electrode immersed in the absence and presence of the optimum concentration of the inhibitors

\begin{tabular}{cccccccc}
\hline $\begin{array}{c}\text { Name } \\
\text { of the } \\
\text { acid }\end{array}$ & Inhibitors & $\begin{array}{c}\beta_{\mathrm{c}} \\
\left.(\mathrm{V} \mathrm{dec})^{-1}\right)\end{array}$ & $\begin{array}{c}\beta_{\mathrm{a}} \\
\left(\mathrm{V} \mathrm{dec}^{-1}\right)\end{array}$ & $\begin{array}{c}\mathrm{E}_{\text {Corr }} \\
(\mathrm{V})\end{array}$ & $\begin{array}{c}\mathrm{I}_{\text {Corr }} \\
\times 10^{-4}(\mathrm{~A})\end{array}$ & $\begin{array}{c}\text { Corrosion } \\
\text { rate, } \\
\mathrm{mmpy}\end{array}$ & $\begin{array}{c}\text { Inhibition } \\
\text { efficiency, } \\
\%\end{array}$ \\
\hline $1 \mathrm{M}$ & Blank & 5.026 & 10.632 & -0.493 & 3.913 & 18.810 & --- \\
$\mathrm{HCl}$ & FB & 7.595 & 15.685 & -0.505 & 1.261 & 6.058 & 67.77 \\
$2 \mathrm{M}$ & Blank & 4.809 & 6.088 & -0.553 & 3.332 & 16.010 & --- \\
$\mathrm{HCl}$ & FB & 5.593 & 16.573 & -0.407 & 2.061 & 9.905 & 38.14 \\
\hline
\end{tabular}

The non-constancy of Tafel slopes for the inhibitor at optimum concentration reveals that the inhibitor action due to the interference in the mechanism of the corrosion processes at cathode. The $I_{\text {corr }}$ values have decreased for the inhibitor at optimum concentration. The inhibition efficiencies determined from the values of corrosion current density and the inhibition efficiency were found to show good agreement with those obtained from weight loss measurements. FB shows the maximum inhibition efficiency of $67.77 \%$ in $1 \mathrm{M} \mathrm{HCl}$ and $38.14 \%$ in $2 \mathrm{M} \mathrm{HCl}$. This result suggests that the addition of inhibitors retards the hydrogen evolution reaction ${ }^{23}$. Hence the $\mathrm{FB}$ acts as a good inhibitor system due to the higher electrostatic attraction over the metal surface. This occur due to the presence of high electron density of the nitrogen (N-H group) atom in the inhibitor molecule. 


\section{Electrochemical impedance spectroscopy (EIS)}

The corrosion of mild steel in $1 \mathrm{M} \mathrm{HCl}$ and $2 \mathrm{M} \mathrm{HCl}$ solution in the presence and absence of formazan of benzaldehyde (FB) was investigated by EIS measurements at open circuit potential condition. Nyquist plots for mild steel obtained at the interface of electrode and electrolyte in the presence and absence of optimum concentration of inhibitors is given in Figure 5(a) \& (b). The Nyquist diagram obtained with $1 \mathrm{M} \mathrm{HCl}$ and $2 \mathrm{M} \mathrm{HCl}$ shows only one capacitive loop and the diameter of the semicircle increases on the increasing the electrostatic attraction of the inhibitor suggesting that the formed inhibitive film was strengthened by the addition of such inhibitors. All the obtained plots show only one semicircle and they were fitted using one time constant equivalent model (Randle's model) with capacitance $(C)$ and charge transfer resistance $\left(\mathrm{R}_{\mathrm{ct}}\right)$. The main parameters deduced from the impedance technique are shown in Table 4.

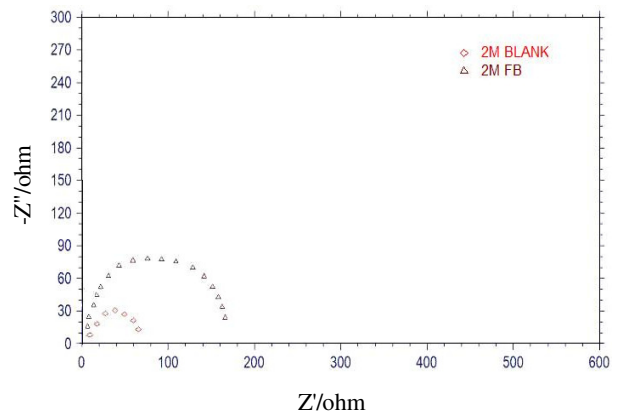

Figure 5(a). A.C. Impedance curves of mild steel electrode immersed in $1 \mathrm{M} \mathrm{HCl}$ in the absence and presence of the inhibitors

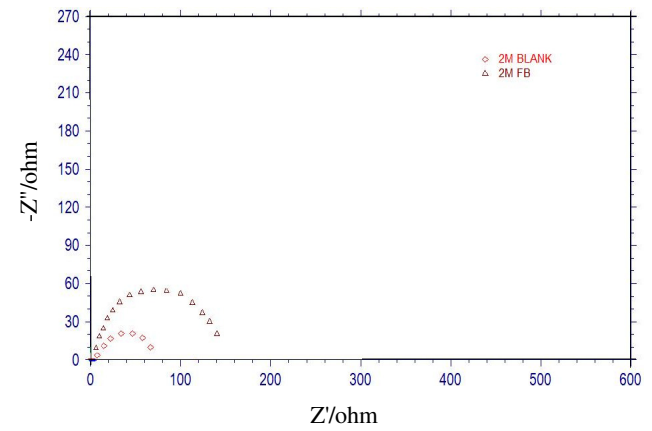

Figure 5(b). A.C. Impedance curves of mild steel electrode immersed in $2 \mathrm{M} \mathrm{HCl}$ in the absence and presence of the inhibitors

Table 4. A.C. Impedance parameters of mild steel electrode immersed in $1 \mathrm{M} \mathrm{HCl}$ in the absence and presence of the inhibitors

\begin{tabular}{|c|c|c|c|c|}
\hline \multirow[b]{2}{*}{$\begin{array}{l}\text { Name of } \\
\text { the acid }\end{array}$} & \multirow[b]{2}{*}{ Inhibitors } & \multicolumn{3}{|c|}{ Parameters } \\
\hline & & $\begin{array}{c}R_{\mathrm{ct}}, \\
\text { ohm cm }\end{array}$ & $\begin{array}{c}\mathrm{C}_{\mathrm{dd}}, \\
\mu \mathrm{F} \times 10^{-5}\end{array}$ & $\begin{array}{c}\text { Inhibition } \\
\text { efficiency, \% }\end{array}$ \\
\hline \multirow{2}{*}{$1 \mathrm{M} \mathrm{HCl}$} & Blank & 72.72 & 4.118 & - \\
\hline & FB & 197.25 & 1.713 & 63.13 \\
\hline \multirow{2}{*}{$2 \mathrm{M} \mathrm{HCl}$} & Blank & 70.12 & 4.618 & - \\
\hline & FB & 107.91 & 2.235 & 35.01 \\
\hline
\end{tabular}

The lower double layer capacitance $\left(\mathrm{C}_{\mathrm{dl}}\right)$ value for $1 \mathrm{M} \mathrm{HCl}$ and $2 \mathrm{M} \mathrm{HCl}$ mediums indicates that the homogeneity of the surface of the mild steel roughened due to corrosion. The double layer capacitance $\mathrm{C}_{\mathrm{dl}}$ values have decreased on the effective addition of different inhibitors at the optimum concentration. The studied system indicates the reduction of charge accumulated in the double layer due to formation of adsorbed inhibitor layer over the metal surface ${ }^{24}$. The inhibiting efficiencies show that the inhibitory actions may be due to the adsorption of the inhibitors on mild steel surface ${ }^{25}$.

The compound investigated FB has been found to give an excellent inhibition due to the electron density on the nitrogen of the N-H group. This leads to the strong electrostatic attraction of FB over the metal surface thereby resulting in the high inhibition efficiency. Generally on the metal side, electrons control the charge distribution whereas on the solution 
side it is controlled by ions. Since ions are much larger than the electrons, the equivalent ions to the charge on the metal will occupy quite a large volume on the solution side of the double layer ${ }^{26}$. From Table 4 it indicates that, the capacitance of the electrical double layer $\left(\mathrm{C}_{\mathrm{dl}}\right)$ decreases in the presence of the inhibitors. Decrease in the $\left(\mathrm{C}_{\mathrm{dl}}\right)$ which can result from a decrease in local dielectric constant and / or an increase in the thickness of the electrical double layer, suggests that the inhibitor molecule may act by adsorption at the metal/solution interface ${ }^{27}$.

\section{FT-IR spectral studies}

FT-IR analyses of metal surface can be useful for predicting whether organic inhibitors are adsorbed or not adsorbed on the metal surface ${ }^{28}$. FTIR spectra were used to support the fact that corrosion inhibition of mild steel in acid medium is due to the adsorption of inhibitor molecules on the mild steel surface as well as providing new bonding information on the steel surface after immersion in inhibited $\mathrm{HCl}$ solution at optimum concentration. Figure 6(a) shows the IR spectrum of the formazan of benzaldehyde (FB). In this spectrum the peak appeared at $3204 \mathrm{~cm}^{-1}$ corresponds to amide $\mathrm{N}-\mathrm{H}$ stretching, $1571 \mathrm{~cm}^{-1}$ corresponds to $\mathrm{C}=0$ group overlapping with $-\mathrm{NH}$ deformation bending, $1412 \mathrm{~cm}^{-1}$ corresponds to $\mathrm{C}-\mathrm{C}$ stretching and $1012 \mathrm{~cm}^{-1}$ corresponds $\mathrm{C}-\mathrm{H}$ in- plane bending. Figure $6 \mathrm{~b}$ is similar to Figure $6 \mathrm{a}$ which indicates the corrosion products contains formazan of benzaldehyde (FB). Therefore from the spectra it is revealed that the inhibition is due to the physical adsorption of corresponding organic molecule.

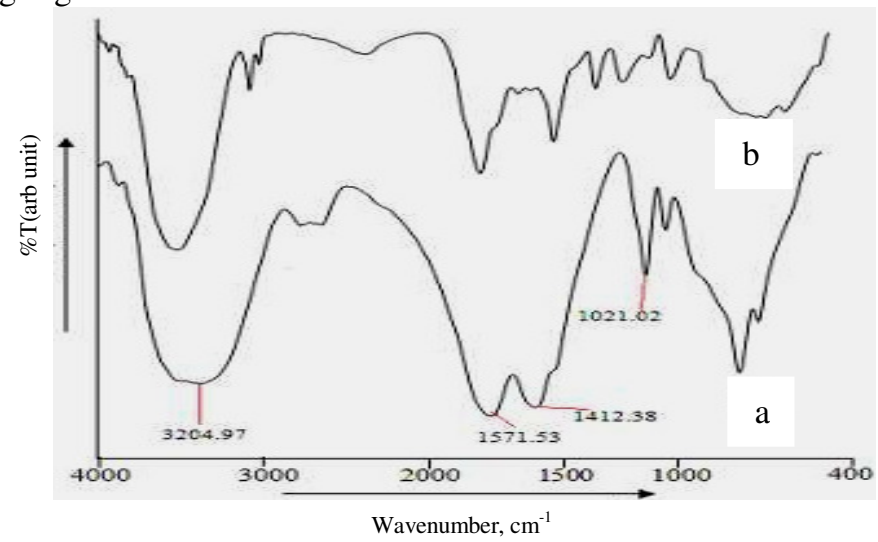

Figure 6. IR spectrum of the corrosion product showing adsorption in the presence of aqueous extract of formazan benzaldehyde (FB) (a: FB; b: Corrosion products contains FB).

\section{SEM analysis}

The polished mild steel specimens were immersed in the acid solution $(1 \mathrm{M} \mathrm{HCl}$ and $2 \mathrm{M} \mathrm{HCl}$ ) and in the acids containing inhibitor formazan of benzaldehyde (FB) for $2 \mathrm{~h}$ and then the specimens were taken out, dried and observed under Scanning Electron Microscope (SEM). The micrograph shown in the Figure $7 \& 8$ which is dipped in blank solution of $1 \mathrm{M} \mathrm{HCl}$ and $2 \mathrm{M} \mathrm{HCl}$ and Figure $9 \& 10$ which is dipped in $36.85 \mathrm{mM}$ concentration of inhibitor solution with $1 \mathrm{M} \mathrm{HCl}$ and $2 \mathrm{M} \mathrm{HCl}$ depicts that the concentration of the inhibitor solution suggesting that the presence of adsorbed layer of the inhibitor on mild steel surface which impedes corrosion rate of metal appreciably. This results in enhanced surface coverage of the metal so that there is a decrease in the contact between metal and the aggressive medium ${ }^{29}$. 


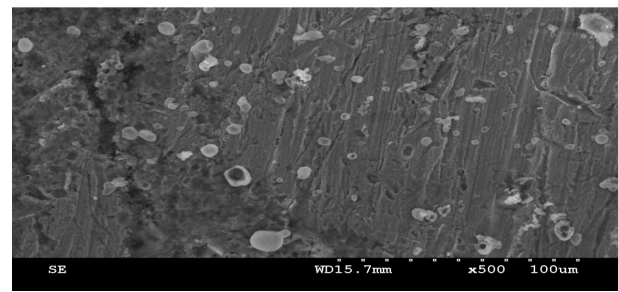

Figure 7. SEM images obtained for the mild steel surfaces immersed for $2 \mathrm{~h}$ in $1 \mathrm{M} \mathrm{HCl}$ (blank acid solution)

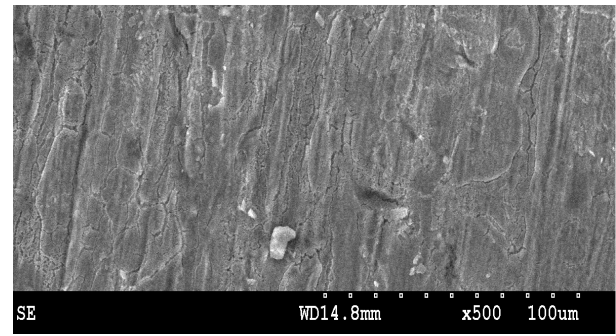

Figure 9. SEM images obtained for the mild steel surfaces immersed for $2 \mathrm{~h}$ in $1 \mathrm{M} \mathrm{HCl}$ with $36.85 \mathrm{mM}$ inhibitor solution

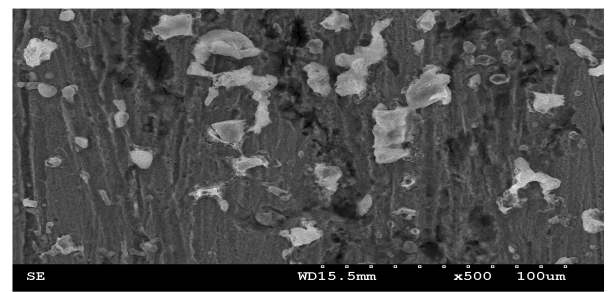

Figure 8. SEM images obtained for the mild steel surfaces immersed for $2 \mathrm{~h}$ in $2 \mathrm{M} \mathrm{HCl}$ (blank acid solution)

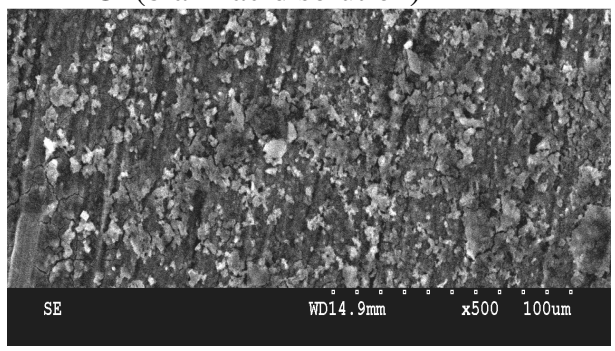

Figure 10. SEM images obtained for the mild steel surfaces immersed for $2 \mathrm{~h}$ in $2 \mathrm{M} \mathrm{HCl}$ with $36.85 \mathrm{mM}$ inhibitor solution

\section{Conclusion}

The present study leads to the following conclusions

1. Formazan of benzaldehyde (FB) was found to be an effective inhibitor in the acidic medium giving inhibition efficiency upto $43.00 \%$ in $1 \mathrm{M} \mathrm{HCl}$ and $37.87 \%$ in $2 \mathrm{M} \mathrm{HCl}$ respectively.

2. The adsorption of the compound investigated follows the Langmuir isotherm and the adsorption is physical in nature.

3. Polarization measurements demonstrate that the compound under investigation (FB) inhibit both anodic and cathodic reaction and hence it acts as a mixed type inhibitor.

4. Impendence measurements indicate that the presence of electron donating group on the inhibitor increases the charge transfer resistance and decreases the double layer capacitance.

5. The type of the substituents group and the type of the functional atoms of the inhibitor molecule are found to play an important role in the inhibition process.

6. Results obtained from weight loss measurements and electrochemical measurements are in good agreement

7. FT-IR analysis confirms that the inhibiton efficiency of the inhibitor in mild steel through electrostatic attraction of inhibitor molecule and the metal surface.

8. The morphological investigation also confirms the effective protection of mild steel, through the less damaged and minimum pits found in the inhibited surface.

\section{Acknowledgement}

Helpful discussions with Professor V.Collins Arun Prakash and Professor K.M.Govindaraju from Mahendra Engineering College are gratefully acknowledged and also I thankful to AMET University and Mahendra Engineering College for providing Lab Facilities to bring out this work. 


\section{References}

1. $\quad$ Ning S G and Shi M L, J Chin Soc Corros Prot., 1990, 10, 383.

2. EI Mehdia B, Mernari B,Traisnel M, Bentiss F and Lagrenee M, Mater Chem Phys., 2002, 77(2), 489-496.

3. Govindaraju K M, Gopi D, Collins Arun Prakash V, Manivannan V and Kavitha L, $J$ Appl Electroche., 2009, 39(2), 269-276.

4. Anand B and Balasubramanian V, J Chem., 2011, 8(1), 226-230.

5. Zerga B, Sfaria M, Rasis Z, Ebn Touhami M, Taleb M, Hammouti B, Imelouane B and Elbachiri A, Mater Tech., 2009, 97, 297.

6. Chaieb E, Bouyanzer A, Hammouti B and Benkadour M, Appl Surf Sci., 2005, 246(1-3), 199-206.

7. Bouklah M and Hammouti B, Port Electrochim Acta, 2006, 24(4), 457.

8. Bouyanzer A, Majidi L and Hammouti B, Phys Chem News, 2007, 37, 70.

9. Matheswaran P and Ramasamy A K, J Chem., 2010, 7(3), 1090-1094.

10. Ferreira E S, Giacomelli C, Gicomelli F C and Spinelli A, Mater Chem Phys., 2004, 83(1), 129-134.

11. Bouklah M, Ouassini A, Hammouti B and EI Idrissi A, Appl Surf Sci., 2006, 252(6), 2178-2185.

12. Anand B, Jayandran M and Balasubramainan V, Asian J Chem., 2011, 23(5), 2106-2108.

13. Anand B and Balasubramainan V, Int J Adv Mater Sci., 2011, 1(1), 1-7.

14. Akrout H, Maximovitch S, Bousselmi L, Triki E and Dalard F, Mater Corros., 2007, 58(3), 202-206.

15. Gopi D, Manimozhi S, Govindaraju K M, Manisankar P and Rajeswari S, J Appl Electrochem., 2007, 37(4), 439-449.

16. Aloui S, Forsal I, Sfaira M, Ebn Touhami M, Taleb M, Filali Baba M and Daoudi M, Portugaliae Electrochim Acta, 2009, 27(5), 599-613.

17. Kustu C, Emregul K C and Atakol O, Corros Sci., 2007, 49(7), 2800-2814.

18. Zhang Q B and Hua Y X, Electrochim Acta, 2009, 54(6), 1881-1887.

19. Abiola O K, Oforka N C and Ebenso E E, Bulletin Electrochem., 2004, 20, 409.

20. Moretti G and Guidi F, Corros Sci., 2002, 44(9), 1995-2011.

21. Bentiss F, Lebrini M and Lagrene M, Corros Sci., 2005, 47(12), 2915-2931.

22. Yurt A, Ulutas S and Dal H, Appl Surf Sci., 2006, 253(2), 919-925.

23. Gunasekaran G and Chauhan L R, Electrochim Acta, 2004, 49(25), 4387-4395.

24. Govindaraju K M, Gopi D and Kavitha L, J Appl Electrochem., 2009, 10, 263-269.

25. Ozcan M, Dehri I and Erbil M, Appl Surf Sci., 2004, 236(1-4), 155-164.

26. Ashassi-Sorkhabi H, Shaabani B and Seifzadeh D, Appl Surf Sci., 2005, 239(2), 154-164.

27. Lagrenee M, Mernari B, Bouanis M, Traisnel M and Bentiss F, Corros Sci., 2002, 44(3), 573-588.

28. Singh A, Singh V K and Quraishi M A, Int J Corros., 2010, DOI: 10.1155/2010/275983.

29. Abd El-Rehim S S, Rwfaey S A, Taha F, Saleh M B and Ahmed R A, J Appl Electrochem., 2001, 31, 429-435. 